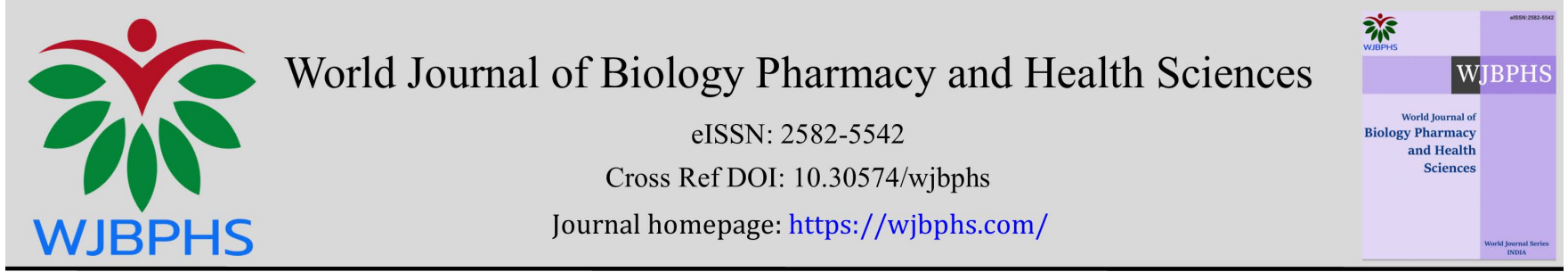

(RESEARCH ARTiCLE)

\title{
Prevalence, intensity and vector dynamics of malaria in Anambra east local government area of Anambra State, Nigeria
}

Udujih Helen Ifeoma ${ }^{1,}$, Dike-Ndudim Joy Nkiru 1, Udujih, Obinna Godwin 2, Dike Uchechi Pamela 2, Amadi Joy Adaku Chibuzo ${ }^{3}$, Ogoamaka Ann Ijeoma ${ }^{4}$ and Onyeneke Esther- Ben Ninikanwa ${ }^{3}$

${ }^{1}$ Department of Medical Laboratory Science, Faculty of Health Science, Imo State University Owerri, Imo State, Nigeria.

${ }^{2}$ Department of Public Health, School Of Health Technology, Federal University Of Technology Owerri, Imo Sate, Nigeria.

${ }^{3}$ Department of Nutrition and Dietetics, Faculty of Health Science, Imo State University Owerri, Imo State, Nigeria.

${ }^{4}$ Department of Microbiology, Faculty of Science, Imo State University Owerri, Imo State, Nigeria.

World Journal of Biology Pharmacy and Health Sciences, 2021, 06(02), 073-080

Publication history: Received on 29 March 2021; revised on 14 May 2021; accepted on 17 May 2021.

Article DOI: https://doi.org/10.30574/wjbphs.2021.6.2.0041

\begin{abstract}
The prevalence, intensity and some vector dynamics of malaria in two communities of Anambra East Local Government Area LGA was carried out using standard parasitological and entomological techniques for rapid assessment of malaria infection, level of parasitaemia and morphological features of mosquitoes. Results showed an overall malaria RDT (Rapid Diagnostic Test) prevalence of 22\% and community based prevalence of $13(30 \%)$ and 22(24\%) for Umuoba Anam and Nando respectively. Overall, age related prevalence in the Anambra West LGA showed that the age bracket 35 to 42 years had the highest malaria prevalence 3(42.9\%). Overall sex related prevalence in Anambra East LGA showed no statistical significance in prevalence among males $(12.0 \%)$ and females $(10.0 \%)(\mathrm{P}<0.05)$. The intensity of malaria infection from each of the communities revealed that both low (50-500 parasites/ $\mu$ l) and medium $(>500-2000$ parasites/ $\mu \mathrm{l}$ ) parasitaemia. There was no high parasitaemia recorded in Umuoba-Anam. Overall, a total of 225 mosquitoes were encountered with anopheles making up $61 \%$. A hundred and twenty one $(53.8 \%$ of the total mosquito population in the study was found to be unfed with blood meal whereas $54(24 \%)$ and $50(22.2 \%)$ were freshly and previously fed respectively. One hundred and twenty one $(53.8 \%)$ of the mosquitoes appeared non-gravid against $82(36.4 \%)$ that are gravid. The mosquitoes encountered were Anopheles gambiae 31(13.8\%), Anopheles funestus 77(34.22\%), and Culex Specie 117(52\%). The two communities recorded variations in prevalence, intensity and vector dynamics. There should be intensified effort to continuously educate the masses on all the strategies of malaria prevention.
\end{abstract}

Keywords: Malaria; Mosquitoes; Anambra state

\section{Introduction}

Malaria is one of the most important public health problems in the world with Nigeria accounting for the greatest number of cases and deaths among all the countries in the world. [1,2]. It is a disease of humans and animals caused by protozoan parasites of the genus plasmodium [3,4]. In humans, malaria is caused by P. falciparium, P. Malariae, P.ovale and p.vivax with $P$. falciparium as the most common cause of human infection responsible for about $90 \%$ of deaths [5]. The female mosquitoes of the Anopheles genus serve as the primary hosts and transmission vectors of the parasites. Malaria is endemic throughout most of the tropical countries with an ongoing transmission in $95 \%$ countries and territories according to [6].

\footnotetext{
* Corresponding author: Udujih Helan

Department of Medical Laboratory Science, Faculty of Health Science, Imo State University Owerri, Imo State, Nigeria. 
In Nigeria, the degree of malaria infection varies from region to region [7]. Transmission rate in the Southern region is approximately uniform throughout the year where it is holendemic in the rural area and mesoendemic in the urban areas [8]. Malaria is the third leading cause of death for children under five years worldwide, after pneumonia and diarrheal disease. There are an estimated 100 million malaria cases with over 300,000 deaths per year in Nigeria compared with 215,000 deaths per year in Nigeria as a result of HIV/AIDS [2]. Due to the nocturnal feeding habits occurs primarily at night protection of man against mosquito bites include the use of mosquito bed nets preferably InsecticideTreated Nets (ITNs), and use of insect repellent on exposed skin [9].

Malaria control in Nigeria has continued to receive huge financial resources from both the government and international bodies over years. Nigeria is one of the malaria endemic countries that have adopted the use of insecticide-treated bed nets as a primary health intervention designed to reduce transmission of malaria. Insecticide-Treated Bed Nets (ITNBs) therefore, have been fairly distributed in both urban and rural areas mostly free of charge. However, malaria has continued to be a major public health problem in the country.

The emphasis devoted to creating awareness on the use of the ITBNs in Nigeria has become such that all other control measures are sidelined and may soon be dropped out of use. There is need therefore, to evaluate the effectiveness of malaria control methods with respect to local environmental factors in the Nigerian communities in order to establish the best control approach for particular environments.

\section{Methods}

\subsection{Study Area}

The study was carried out in Anambra East Local Government Area (LGA) in Anambra State. A total of two villages (Nando and Umuoba Anam) were selected for the study. The communities selected were communities currently under the Neglected Tropical Diseases (NTDs) elimination program [10]. The study communities lie within the humid tropical rainforest belt of south eastern Nigeria. The main occupation of the people is fishing, subsistence farming and trading. The nature of their occupation predisposes them to frequent mosquito bites.

\subsection{Ethical Considerations}

An advocacy visit was made to the traditional head of the selected village for mobilization and support. Letter of intent was sent to the stake holders in the selected villages. Ethical approval was obtained from the State Ministry of Health Anambra State.

\subsection{Study design}

The study design and method was adapted to that by [11]. This involved malaria cross sectional survey of 174 randomly recruited subjects (75 males and 99 females) from age 1 year and above using rapid diagnostic assay kits for $P$. falciparum, thick and thin films. A pre-tested questionnaire was administered to obtain demographic information.

\subsection{Sample Collection and Examination}

Two sets of $20 \mu \mathrm{l}$ of capillary blood were collected from the center finger employing a capillary. Ten micro litres of blood each was dropped on SD Bioline immunochromatographic test kits for P. falciparum Ag HRP2 antigen. Two micro litres of blood was dropped on the outer end of the slide for thin film making while six micro litres was used to make a thick film on the inner part of the slide. The thin film was fixed in $70 \%$ methanol. All blood films were stained using $3 \%$ Giemsa stain for 30 minutes [12].

The stained slides were sent to the laboratory to be viewed microscopically for Plasmodium detection, speciation and parasite count. The films were counted by employing a four digit hand tally counter and Olympus microscope.

Parasite density was calculated and reported according to WHO (2015) with little modification in grading as; low (50500 parasites/ $\mu \mathrm{l}$ ), medium (>500-2000 parasites/ $\mu \mathrm{l})$ and high (>2000- 250000parasites/ $\mu$ l) using the formula: Parasite count x 8000 /set range of WBC and \%parasitaemia=parasitized red cell/set range of RBCs X 100.

A total of eighty (80) rooms were selected for mosquito knock down with in the study. All the compounds in each community were numbered and twenty (20) compounds out of the even numbered compounds were selected systematically. In each of the chosen compounds, the space where the highest number of persons slept was selected. Out of the eighty rooms selected for knock down, forty were from houses with block walls, ceiling and closed eaves 
whereas the other forty were from those with open eaves with or without ceiling. The former was designated improved houses while the later was named unimproved houses. Each group was further divided into people who use ITBN and people that use window net as vector control measure.

Indoor resting mosquitoes were sampled between 06:00AM and 10:00AM using Pyrethrum Spray Catches (PSC) method [13].In each room, a pyrethrum insecticide was sprayed into the space with window and doors closed; mosquito collection was made after about 10 minutes on a white cloth following knock-down. Mosquitoes were identified morphological key of [14] and counted, noting their physiological stages [15].

\section{Results}

\subsection{Malaria study result}

Overall, Anambra East LGA recorded an overall malaria prevalence of $22.00 \%$ out 100 subjects tested. The number of individuals tested for malaria in Umuoba-Anam village was 47(47.00\%), out of which 14(29.79\%) was positive. Fifty three (53.00\%) individuals were tested in Nando village and 8(15.09\%) were positive (Table 1).

Table 1 Overall RDT (Rapid Diagnostic Test) prevalence of malaria in the study population

\begin{tabular}{|l|c|c|c|}
\hline Community & No. of tested & No. of positive & Prevalence \\
\hline Umuoba-Anam & $47(17.2 \%)$ & $14(25 \%)$ & 30.0 \\
\hline Nando & $53(19.3 \%)$ & $8(14 \%)$ & 15.1 \\
\hline Total & 100 & 22 & 22 \\
\hline
\end{tabular}

Overall sex related prevalence in Anambra East LGA showed no statistical significance in prevalence among males $(12.0 \%)$ and females (10.0\%) P>0.05. In Umuoba-Anam, a prevalence of $64 \%$ was recorded among males out of 26 tested whereas females recorded a prevalence of $36 \%$ out of 21 tested. In Nando village, the number of males tested was 20 , out of which 3 were positive with malaria prevalence of $37.5 \%$ while 5 females tested positive out of 33 with giving a prevalence of $62.5 \%$.

Table 2 Age related malaria prevalence in Umuoba-Anam village

\begin{tabular}{|c|c|c|c|}
\hline Age range & No. of tested & No. of positive & Prevalence \\
\hline $1-7$ & 9 & 3 & 21.4 \\
\hline $7-14$ & 7 & 4 & 29.0 \\
\hline $14-21$ & 2 & 0 & 0.0 \\
\hline $21-28$ & 7 & 1 & 7.1 \\
\hline $28-35$ & 7 & 1 & 7.1 \\
\hline $35-42$ & 3 & 2 & 14.0 \\
\hline 42 and above & 12 & 3 & 21.4 \\
\hline Total & 47 & 14 & 30 \\
\hline
\end{tabular}

Overall, age related prevalence in the Anambra East LGA showed that the age bracket 35 to 42 years had the highest malaria prevalence $3(42.9 . \%)$ followed by the age range $1-7$ years $7(29.2 \%)$ while subjects in the age bracket $21-28$ had the least $1(10.0 \%)$.

Age related malaria prevalence in Umuoba-Anam village showed the highest prevalence, 29\% was recorded among age group 7 to 14 years. This was followed by a prevalence of $21.4 \%$ recorded in two age groups, 0 to $7 \&$ those above 42 year. Two (2) persons were positive out of 3 tested in age group 35 to 42 years, giving a prevalence of $14.0 \%$. Age groups 21 to 28 and 28 to 35 years had the same population ( 7 each), same number testing positive ( 1 each) and with same prevalence of $7.1 \%$. Only 2 individuals were tested among age group 14 to 21 years and they were both negative. 
Age related prevalence of malaria in Nando village showed that fifteen individuals were tested among age group 0 to 7 years with 4 testing positive. This gave the highest age related prevalence of $50 \%$ in the village. It was followed by $25 \%$ prevalence recorded among age group 42 years and above, having 2 persons positive out of 16 tested. Both age groups, 14 to 21 years and 35 to 42 years had $12.5 \%$ prevalence. Eight (8) individuals were tested among age group 7 to 14 years, three (3) among 21 to 28 years and five (5) among group 28 to 35 years; none among these groups tested positive for malaria.

Table 3 Age related malaria prevalence in Nando village

\begin{tabular}{|c|c|c|c|}
\hline Age range & No. of tested & No. of positive & Prevalence \\
\hline $1-7$ & 15 & 4 & 50 \\
\hline $7-14$ & 8 & 0 & 0 \\
\hline $14-21$ & 2 & 1 & 12.5 \\
\hline $21-28$ & 3 & 0 & 0 \\
\hline $28-35$ & 5 & 0 & 0 \\
\hline $35-42$ & 4 & 1 & 12.5 \\
\hline 42 and above & 16 & 2 & 25 \\
\hline Total & 53 & 8 & 15.1 \\
\hline
\end{tabular}

The intensity of malaria infection from each of the four communities is represented in figure 1. Umuoba-Anam recorded the highest frequency of low and medium malaria density. There was no high parasitaemia recorded in Umuoba-Anam.

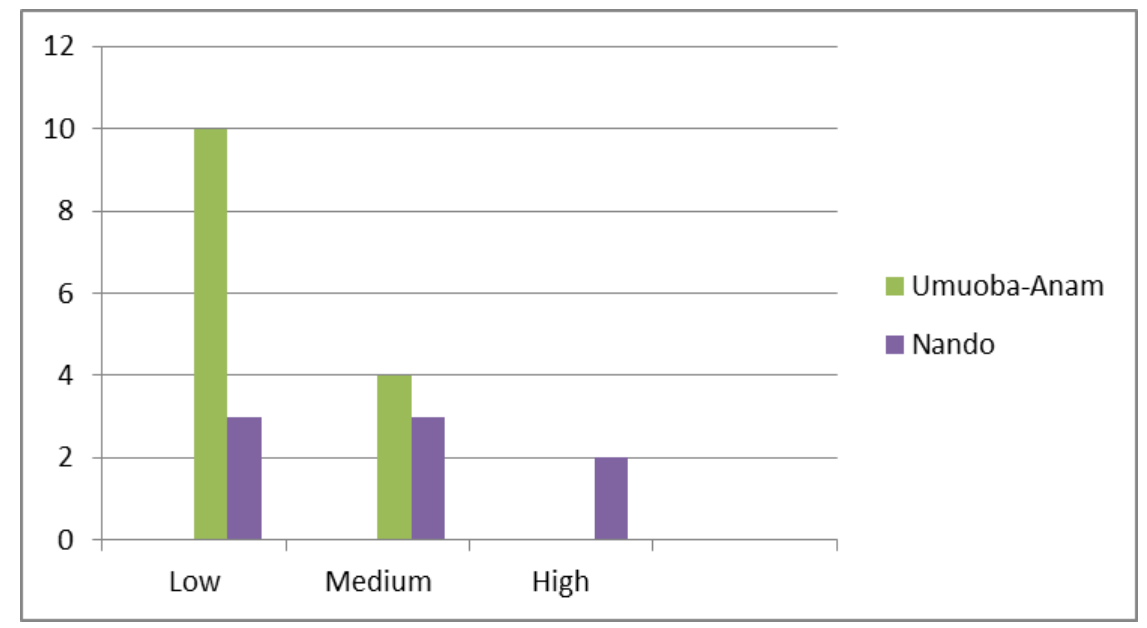

Figure 1 Intensity of Plasmodium parasitaemia in the study

\subsection{Entomological result}

The distribution of mosquito species encountered in the study areas showed a total of 225 mosquitoes encountered in the study; the Culex Species made up 52\% of the total mosquitoes identified, while Anopheles funestus and Anopheles gambiae sl made up $34.2 \%$ and $13.8 \%$ respectively.

Physical characteristics of mosquitoes identified in Umuoba-Anam showed 57\% of the unfed group as Culex, 32\% Anopheles funestus, and 11\% Anopheles gambiae sl; 60\% of the freshly fed group as Culex, 23\% Anopheles funestus and 17\% Anopheles gambiae sl, while the previously fed are 39\%(Culex), 32\%(Anopheles funestus) and 29\% (Anopheles gambiae sl). The Culex species recorded the highest number in both gravid and non-gravid $(64.2 \%$ and $44 \%$ respectively) groups, followed in the same pattern by Anopheles funestus (25.4\% and 32\%) and Anopheles gambiae $(10.4 \%$ and $21 \%)$. Umuoba-Anam recorded a total of $81(58 \%)$ unfed, $30(22 \%)$ freshly fed, 28(20\%) previously fed, 67(48\%) gravid and 72(52\%) non-gravid mosquitoes. (figure3). 


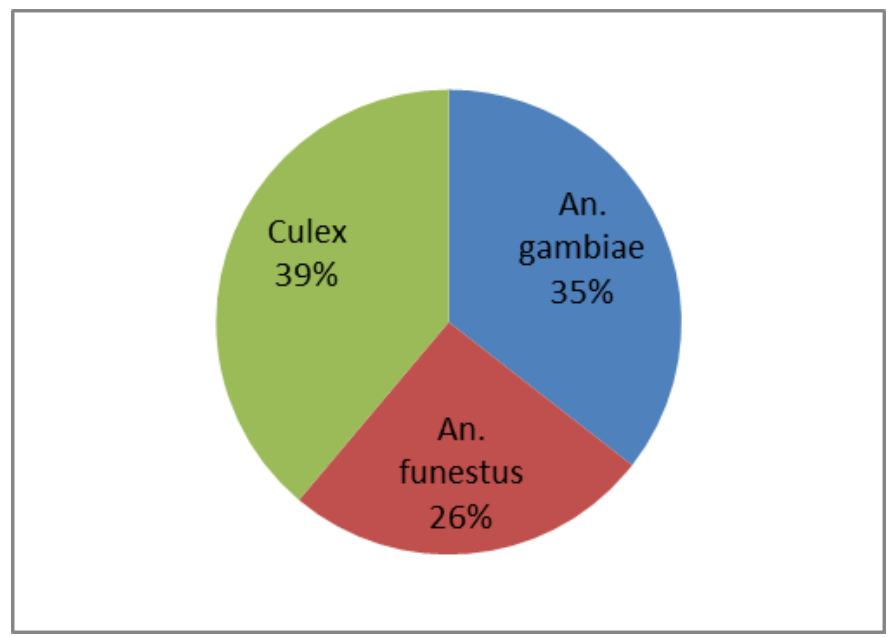

Figure 2 Distribution of mosquito species identified in the study areas

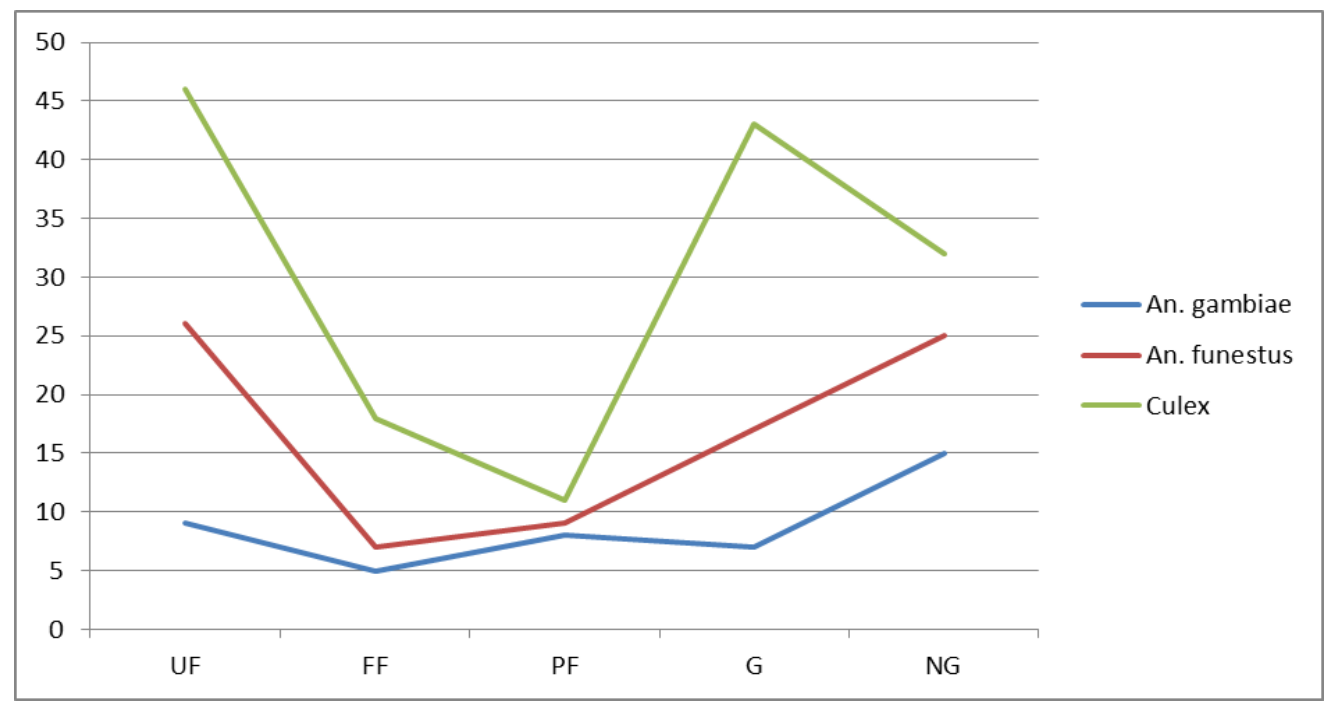

Figure 3 Physical characteristics of mosquito species identified in Umu Oba-Anam

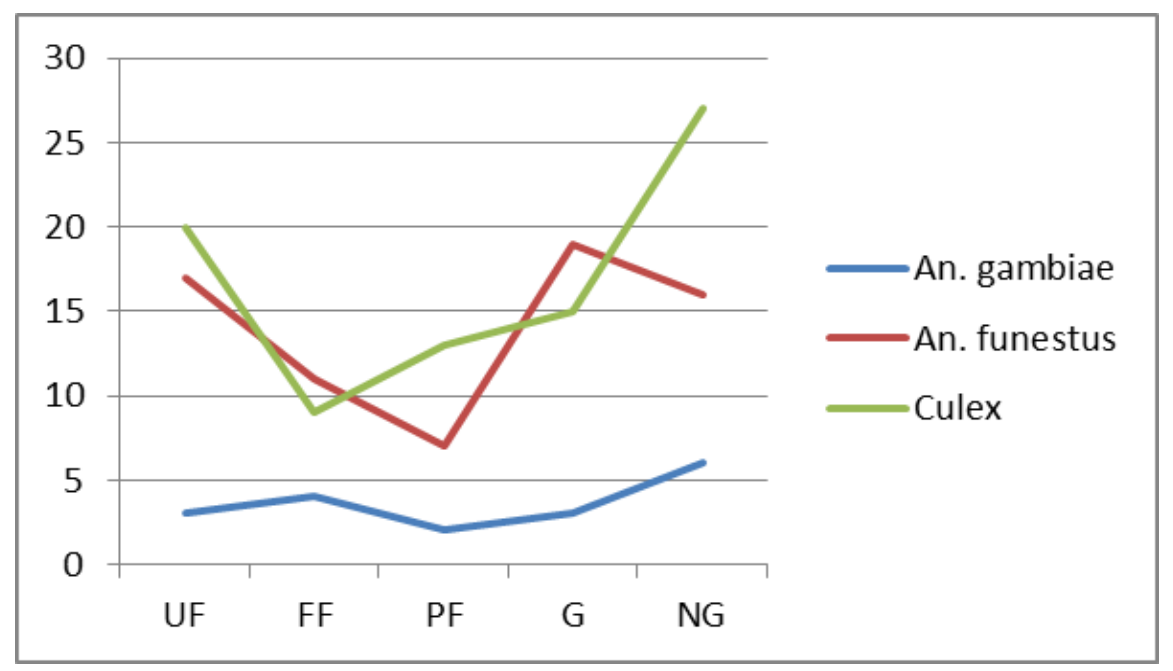

Figure 4 Physical characteristics of mosquito species identified in Nando community. 
Nando village had showed Unfed: Culex 50\%, Anohpeles funestus 42.5\%, and Anopheles gambiae 7.5\%; freshly fed: Anopheles funestus 46\%, Culex 37\% and Anopheles gambiae sl 17\%; previously fed: Culex 59\%, Anopheles funestus 32\%, and Anopheles gambiae 9\%; Gravid: Anopheles funestus 51\%, Culex 41\% and Anopheles gambiae sl 8\%; Non-gravid: Culex 55\%, Anopheles funestus 33\% and Anopheles gambiae sl 12\%. In general, Nando village recorded 4(46\%) unfed, $24(28 \%)$ freshly fed, 22(26\%) previously fed, 15(43\%) gravid and 49(57\%) non- gravid mosquitoes. (Figure 4).

\section{Discussion}

Malaria is endemic throughout most of the tropical countries with an ongoing transmission in 95\% countries and territories [6]. This study in two villages in Anambra East Local Government Area has confirmed an ongoing malaria transmission in the area. The prevalence of malaria was found to be $22 \%$. This figure is far lower than other studies conducted previously in the state [16,17]. The result is however similar to $24.49 \%$ and $22 \%$ recorded in 2017 and 2020 respectively by Udujih et al. [4], and $21 \%$ recorded by Dike- Nduduim et al [11] in the same state. This is an indication of a progressive reduction in malaria prevalence as reflected also in the Nigeria Malaria Indicator Survey where a RDT prevalence of 52\% was recorded in 2010 and 45\% recorded in 2015 [18,19].

The prevalence of malaria varied between the two communities with Umuoba-Anam village recording a statistically significant higher prevalence $(\mathrm{P}<0.05)$. Population cluster is one of the factors that contribute to variations in malaria prevalence. These variations also could be attributed to other factors like proximity to water bodies which act as breeding sites of mosquito vectors, use of Insecticide treated bed net and poorly finished housing.

This study observed higher malaria prevalence in males than in females. The observed difference was statistically insignificant. Overall age-related malaria prevalence was highest among the age bracket 35 to 42 years (42.9\%) followed by those in the age bracket 1-7 years (29.2\%). This contradicts finding where children below age $10 y e a r s$ had the highest prevalence $[20,21,22]$. This disparity could be attributed to the increased rate of ITN use among the vulnerable group of which children below the age of 10 years are among.

Malaria parasite densities recorded in this study were mostly below 2,000 parasites/ $\mu \mathrm{L}$ of blood with many cases falling below 500 parasites $/ \mu \mathrm{L}$. According to [23], asymptomatic parasitaemia may occur in high transmission areas after childhood where sub-microscopic plasmodium serve as a silent reservoir of disease, sustaining a low level of remnant malaria in the population.

All the mosquitoes in this study were caught inside the houses confirming their anthropophagic, endophagic and endophilic feeding habits. The blood meal and abdominal condition is also a strong evidence of a continuous humanvector contact, on-going disease transmission and a sustained reproduction of the vectors in the area. Only Anopheles and Culex mosquitoes were identified in the present study. Anopheles gambiae, An. funestus made up 61\% of the total mosquito population against 39\% by the Culex species. This is in agreement with the findings of [24] and [25] who reported Anopheles species to be more dominant in other parts of the country. Culex species have been found by [26] to be dominant in some parts of Anambra State. Anambra State is a densely urbanized region of the country which may account for the high number if Culex species. The number of Culex mosquito identified in the study areas suggests that there is urbanization of the area as these mosquitoes have a predilection for urban environment.

\section{Conclusion}

It is evident from this study that malaria transmission is still ongoing in the study area. Mosquito-proofing of houses should become the central plank of malaria control activities in the tropical countries. Apart from the fact that mosquitoes are possibly becoming resistant to the insecticides used in treating bed nets, the effectiveness of insecticide treated bed net is also limited by the fact that it is primarily designed to protect individuals who are sleeping from mosquito bite. Most mosquito bites take place within the house from dusk, when people are still busy with activities such as cooking, eating, reading, relaxing, etc. as such any measure taken to keep mosquitoes from entering the house therefore, should be given more attention. 


\section{Compliance with ethical standards}

\section{Acknowledgments}

We acknowledge the support of Tertiary Education Trust Fund of NigeriaImo State University Management and IBR committee, The Ministry of Health of Anambra State and Research and Publication Team of the Faculty of Health Science, Imo State University Owerri

\section{Disclosure of conflict of interest}

We declare there is no conflict of interest.

\section{Statement of informed consent}

Informed consent was obtained from all individual participants included in the study.

\section{References}

[1] Sabina K. Prevalence and Epidemiology of malaria in Nigeria: A Review, International Journal of Research in Pharmacy and Biosciences. 2017; 4(8): 10 -12.

[2] United State Embassy In Nigeria. Nigeria malaria fact sheet. 2016.

[3] Ukaegbu CO, Nnachi AU, Mawak JD, Igwe CC. Incidence of Concurrent Malaria and Typhoid fever Infections in Febrile patients inJos, Plateau state Nigeria. International Journal of Scientific and Technology Research. 2014; 3(4): 157-161.

[4] Udujih HI, Amaechi AA, Nwoke BEB, Uduji OG, Iwuala CC. Studies on Malaria and Insecticide Treated Bednet Compliance among Primary School Aged Children in Anambra State, Nigeria International Journal of Science and Research methodology. 2017; 8(1): 43 - 52.

[5] Mockenhaupt F, Erhardt S, Burkhardt J, Bosmotive S, Larea S, Anemana S, Otchwemah R. Crammer manifestation and outcome of severe malaria in children in Northern Ghana. American Journal of Tropical Medicine and Hygiene. 2014; 71(2): 167 - 172.

[6] World Health Organisation World malaria report: World Health Organization (WHO) press, Geneva. 2015.

[7] Onwuemele A. An assessment of the spatial pattern of malaria infection in Nigeria. International Journal of Medicine and Medical Sciences. 2014; 6(2): 80-86.

[8] Nworgu OC, Orajiakba BN. Prevalence of malaria in Children 1-10years in Communities in Awka North L.G.A Anambra State South East Nigeria. International Multidiscipinary Journal, Ethiopia. 2011; 5(5): 264-281.

[9] Centres for Disease control and Prevention. Malaria. CDC Global Health Newsletter. 2019

[10] Federal Ministry of Health. Guidelines for malaria- lymphatic filariasis co-implementation in Nigeria. 2013.

[11] Dike- Ndudim JN, Udujih HI, Anikwo ES, Amah HC, Okorie HM, Udujih OG, Obikwelu E, para AU, Nwosu DC, Nwanjo HU. Prevalence, Intensity and some vector dynamics of malaria in Ogbaru Local Government area of Anambra State. World Journal of Advanced Research and Reviews. 2020; 08(02): 072-080. . 2020; 8(2): 72-80.

[12] Cheesebrough M. Malaria Parasite tests in District Laboratory Practice in Tropical Countries.BulterworthHeinemann Ltd., Oxford, UK, (2nd edition). 2010.

[13] Harrison JE, Mathenge EM, Misiani GO, Mukabana WR, Day JF. A simple method for sampling indoor-resting malaria mosquitoes Anopheles gambiae and Anopheles funestus(Diptera:Culicidae) in Africa. Journal of Medical Entomology. 2006; 43(3): 473-479.

[14] Gillies M.T. and Coetzee M. Supplement to the Anophelinae of Africa South of Sahara. Johannesburg publications of the South African Institute For Medical Research1987; 55:1-143

[15] World Health Organization Methods and Techniques: Manual on Practical entomology in Malaria Part II. World Health Organization Offset Publication, Geneva 13. 1975. 
[16] Onyido, A.E., Obinatu, S.C., Umeanato, P.U., Obiukwu, M.O. and Egbuche, M.C. Malaria prevalence and mosquito vector Abundance in Uli town, Ihiala local government area, Anambra state, Nigeria. African Journal Of Biomedical Research, 2011; 14:175-182.

[17] Okeke OP, Imaukwu CA, Eyo JE, Okeafor FC. Prevalence of malaria infection in children in Anambra state Nigeria after change of policy from presumptive/clinical to confirmed diagnosis.African Journal Online. 2016; 13(1): 2385-2391.

[18] Nigeria Malaria Indicator Survey. 2010 Atlas of key indicator.

[19] Nigeria Malaria Indicator Survey. 2015 Atlas of key indicator.

[20] Houmsou, R.S., Amuta, E.U., Sar, T.T. and Adagba A.H Malaria infection among patients attending semi-urban based hospital and performance of HRP-2PF rapid diagnostic test (RDT) in screening clinical cases of Plasmodium falciparium malaria. Translational Biomedicine 2010

[21] Udujih HI, Amaechi AA, Nwoke BE, B, Ajero CMU, Udujih OG, Iwuala CC. Studies on Malaria, BancroftianFilariasis and Insecticide Treated Bed Nets in MmiataAnam, Anambra West Local Government Area, Nigeria. International Journal of Current Microbiology and Applied Sciences. 2019; 8(10).

[22] Oduola AO, Adelaya OJ, Aiyegbusi ZO, Tola M, Obembe A, Ande AT, Awolola S. Dynamics of Anopheline vector species composition and reported malaria cases during rain and dry seasons in two selected communities of Kwara State. Nigeria Journal of Parasitology. 2016; 37(2).

[23] World Health Organisation World malaria report: World Health Organization (WHO) press, Geneva. 2011

[24] Bunza MD, Suleiman AA, Yusuf AM, Bala A. Relative abundance of mosquito species in Kastina metropolis Nigeria.Nigeria Journal of Parasitology. 2010; 31(2): 73-78.

[25] Okonkwo NJ, Obiechina IO, Ugba CN, Irikannu KC, Obianumba SN, Okoye-Uzochukwu CI, Iwuora OI, Chinweke JO. Mosquito species composition in Oba, Idemili South local government area of Anambra state. Reseacher. 2014; 6(8): 51-56.

[26] Federal Ministry of Health Nigeria 2015. Neglected Tropical Diseases Nigeria multi-year master plan 2015-2020 